\title{
Transatlantica
}

Revue d'études américaines. American Studies Journal

\section{Claudine Thomas. Norman Mailer. Le complexe} d'Osiris.

Paris : Belin, 1997. 128 p.

\section{André Bleikasten}

\section{OpenEdition}

Journals

Édition électronique

URL : http://journals.openedition.org/transatlantica/727

DOI : $10.4000 /$ transatlantica.727

ISSN : $1765-2766$

Éditeur

AFEA

Référence électronique

André Bleikasten, «Claudine Thomas. Norman Mailer. Le complexe d'Osiris. », Transatlantica [En ligne], 1 । 2003, mis en ligne le 05 avril 2006, consulté le 29 avril 2021. URL : http://journals.openedition.org/ transatlantica/727 ; DOI : https://doi.org/10.4000/transatlantica.727

Ce document a été généré automatiquement le 29 avril 2021.

\section{c) (i) $\Theta$}

Transatlantica - Revue d'études américaines est mis à disposition selon les termes de la licence Creative Commons Attribution - Pas d'Utilisation Commerciale - Pas de Modification 4.0 International. 


\section{Claudine Thomas. Norman Mailer. Le complexe d'Osiris.}

Paris : Belin, 1997. 128 p.

André Bleikasten

Peut-on faire tenir un océan dans un gobelet? A l'impossible nul n'est tenu, mais on peut toujours essayer. Comme d'autres avant et après elle, Claudine Thomas s'est vaillamment employée à rendre compte d'une oeuvre monumentale dans les 128 petites pages que « Voix américaines » (collection, à présent riche de plus de cinquante titres, dirigée par Marc Chénetier d'une main de fer à peine gantée de velours) alloue à chacun de ses auteurs. Aujourd'hui octogénaire, Norman Mailer, encore que toujours alerte, n'est plus « l'enfant terrible » des lettres américaines, et le moment est peut-être venu de tenter un premier bilan de cet « itinéraire tumultueux, fait de succès confirmés et de ratages, de prises de position généreuses et de considérables outrances, de défis proposés à l'écriture et de perpétuels retours à certains thèmes obsédants ». Personne en France n'était mieux armé(e) pour le faire que Claudine Thomas. Bref par nécessité, son ouvrage n'en réussit pas moins à faire le tour de son sujet. Une connaissance intime de tous les textes de Mailer s'allie ici à une intelligence critique jamais en défaut. Les analyses et les commentaires proposés procèdent de toute évidence d'une longue réflexion patiemment affinée, l'admiration n'y aveugle jamais le jugement et ce qui frappe d'emblée dans cette lecture de Mailer est sa constante justesse. Dès la première page on nous avertit que dans sa production «le pire côtoie le meilleur " et dès le premier chapitre le lecteur commence à entrevoir les paradoxes, les contradictions et les impasses d'une oeuvre follement ambitieuse. Oeuvre de romancier, mais pas seulement. Lire Mailer, note Claudine Thomas, «c'est s'intéresser aux avatars d'une écriture plutôt qu'aux seules tribulations d'un romancier parfois en mal de roman » et «c'est aussi trouver sur son chemin la personne de l'écrivain ».

Une écriture inquiète, en quête d'elle-même, toujours en mouvement et en métamorphose. Un écrivain comédien-caméléon, dans la multiplicité chatoyante de ses rôles et de ses identités, toujours en représentation sinon à la parade : Claudine Thomas ne perd de vue ni l'une ni l'autre, et, mine de rien, elle a su prendre la mesure de la 
démesure de cette entreprise, dont elle suit attentivement le cours et démonte soigneusement les rouages, de The Naked and the Dead jusqu'à Oswald's Tale. (On lui pardonnera de ne pas être allée jusqu'au décevant Gospel according to the Son, tout juste mentionné à la fin; dans la réécriture des évangiles Pasolini et Saramago ont fait nettement mieux). Sa grande familiarité avec l'ensemble de l'oeuvre de Mailer lui permet de mettre en évidence à la fois la constance quasi obsessionnelle de ses enjeux et le renouvellement incessant de ses stratégies. Qu'il s'agisse de fiction ou de «faction", de textes autobiographiques, de reportages ou d'enquêtes, chez Mailer la scène d'écriture se laisse rarement dissocier du «théâtre du moi ». Mais cet égotiste macho-parano-mégalomane, ce bateleur ivre, souvent bouffonnant et un rien énergumène est également l'un des chroniqueurs les plus impitoyablement lucides de l'Amérique, de ses rêves et de ses cauchemars, et comme le dit Claudine Thomas au terme de sa belle étude, « un guetteur infatigable du siècle ».

\section{INDEX}

Thèmes : Recensions

\section{AUTEUR}

\section{ANDRÉ BLEIKASTEN}

Université Marc Bloch - Strasbourg II 